\title{
A Neuronal Form of the Cell Adhesion Molecule L1 Contains a Tyrosine-Based Signal Required for Sorting to the Axonal Growth Cone
}

\author{
Hiroyuki Kamiguchi and Vance Lemmon \\ Department of Neurosciences, Case Western Reserve University, Cleveland, Ohio 44106
}

\begin{abstract}
The neural cell adhesion molecule L1, which is present on axons and growth cones, plays a crucial role in the formation of major axonal tracts such as the corticospinal tract and corpus callosum. L1 is preferentially transported to axons and inserted in the growth cone membrane. However, how L1 is sorted to axons remains unclear. $\mathrm{Tyr}^{1176}$ in the L1 cytoplasmic domain is adjacent to a neuron-specific alternatively spliced sequence, RSLE (Arg-Ser-Leu-Glu). The resulting sequence of YRSLEE conforms to a tyrosine-based consensus motif $(Y x x L)$ for sorting of integral membrane proteins into specific cellular compartments. To study a possible role of the YRSLE sequence in L1 sorting, chick DRG neurons were transfected with human L1 cDNA that codes for full-length $\mathrm{L} 1$ ( $\left.\mathrm{L} 1_{\mathrm{FL}}\right)$, a non-neuronal form of $\mathrm{L} 1$ that lacks the RSLE sequence ( $\left.\mathrm{L} 1_{\Delta \mathrm{RSLE}}\right)$, mutant $\mathrm{L} 1$ with
\end{abstract}

a Y1176A substitution ( 1 $_{\text {Y1176A }}$ ), or L1 truncated immediately after the RSLE sequence $\left(L 1_{\Delta C 77}\right) . L 1_{F L}$ and $L 1_{\Delta C 77}$, both of which possess the YRSLE sequence, were expressed in the axonal growth cone and to a lesser degree in the cell body. In contrast, expression of both $\mathrm{L}_{\triangle \mathrm{RSLF}}$ and $\mathrm{L}_{\mathrm{Y} 1176 \mathrm{~A}}$ was restricted to the cell body and proximal axonal shaft. We also found that $L 1_{\triangle R S L E}$ and $L 1_{Y 1176 A}$ were integrated into the plasma membrane in the cell body after missorting. These data demonstrate that the neuronal form of $L 1$ carries the tyrosinebased sorting signal YRSLE, which is critical for sorting $L 1$ to the axonal growth cone.

Key words: neural cell adhesion molecule; L1; axon; growth cone; protein sorting; tyrosine-based sorting signal
The neural cell adhesion molecule L1 is a transmembrane protein belonging to the immunoglobulin (Ig) superfamily (Moos et al., 1988). The amino acid sequence of the cytoplasmic domain of L1 is identical among mammalian species (Hlavin and Lemmon, 1991). The L1 gene is composed of 28 exons, two of which (exons 2 and 27) are alternatively spliced (Reid and Hemperly, 1992; Takeda et al., 1996). The exon 27 encodes the four amino acids Arg-Ser-Leu-Glu (RSLE) near the middle of the cytoplasmic domain (Miura et al., 1991), which is expressed in neurons but not in the other L1-expressing cells, such as Schwann cells, melanocytes, and lymphocytes (Takeda et al., 1996).

L1 is involved in various important processes during nervous system development, including neuronal migration (Lindner et al., 1983; Barami et al., 1994), neurite growth (Lagenaur and Lemmon, 1987), and neurite fasciculation (Stallcup and Beasley, 1985). L1 is expressed on the surface of axonal shafts and growth cones of developing neurons. Homophilic binding of L1 molecules is probably its most common mode of action in promoting axonal extension along a bundle of preexisting axons, forming fascicles (Grumet and Edelman, 1988; Lemmon et al., 1989). In humans, mutations of the L1 gene cause X-linked hydrocephalus, in which defects of the corticospinal tract and corpus callosum are also found (Wong et al., 1995b). Similar malformations have been

\footnotetext{
Received Dec. 29, 1997; revised March 3, 1998; accepted March 5, 1998.

This work was supported by National Institutes of Health Grants EY-5285 and NS-34252 to V.L. We acknowledge the excellent technical assistance of Guanghui Cheng, Maryanne Pendergast, and Zhenhua Miao. The anti-human L1 antibody (5G3) was the kind gift of Dr. Ralph Reisfeld. We also thank Dr. Martin Snider and Dr. Susan Burden-Gulley for helpful comments on this manuscript.

Correspondence should be addressed to Vance Lemmon, Department of Neurosciences, Case Western Reserve University, 2109 Adelbert Road, Cleveland, OH 44106-4975.

Copyright (C) 1998 Society for Neuroscience $\quad 0270-6474 / 98 / 183749-08 \$ 05.00 / 0$
}

reported in the L1 knock-out mouse (Cohen et al., 1997; Dahme et al., 1997). The dramatic alterations in the formation of major axonal tracts after mutations in the L1 gene clearly demonstrate that L1 plays a crucial role in nervous system development.

During the period when axons elongate toward their proper targets, their tips form a specialized sensory structure called the growth cone, which interacts with environmental cues to produce directed axonal growth. Growth cones undergo rapid changes in shape with concomitant reorganization of cytoskeletal elements when they encounter L1 borders in a substrate (Burden-Gulley et al., 1995; Burden-Gulley and Lemmon, 1996). Consequently, the growth cone is well positioned as the major site of action of L1, where in response to extracellular ligand binding, L1 generates intracellular signals and interacts with the cytoskeleton to regulate axonal growth (Kamiguchi and Lemmon, 1997).

Immunohistochemical analyses of developing mice demonstrated the polarized expression of L1 in pyramidal cells, granule cells, and interneurons in the hippocampus. L1 is expressed on axons but not on dendrites or cell bodies of these cells (Persohn and Schachner, 1990). Furthermore, Vogt et al. (1996) have shown that $\mathrm{NgCAM}$, a chick homolog of $\mathrm{L1}$, is transported directly to the axonal growth cone of dorsal root ganglia (DRG) neurons and inserted exclusively in the growth cone membrane. Subsequently, $\mathrm{NgCAM}$ spreads from the growth cone into the axonal shaft as the axon elongates by preferentially adding new membrane components into the growth cone (Craig et al., 1995). As a result, L1 is preferentially localized in the axonal growth cone and axonal shaft. This raises the question as to how L1 is sorted into a specific population of transport vesicles destined for the axonal growth cone.

It is thought that many proteins carry sorting information encrypted within their structure (Rothman and Wieland, 1996). 
In some cases, the sorting information consists of structural motifs known as sorting signals, which are recognized by intracellular receptor-like molecules. Interaction of a sorting signal with its receptor results in sorting of the signal-bearing protein into a specific population of vesicles destined for a specific cellular compartment. A well known example is a tyrosine-based sorting signal that conforms to the motif $\mathrm{Yxx} \phi$, where $\mathrm{x}$ is any amino acid and $\phi$ is an amino acid with a bulky hydrophobic side chain (Trowbridge et al., 1993). The tyrosine and $\phi$ residues are critical, whereas the importance of the $\mathrm{x}$ residues is less well defined (Boll et al., 1996; Ohno et al., 1996). Various protein-sorting events have been attributed to the tyrosine-based sorting signals, which include clathrin-mediated endocytosis, targeting to endosomes en route to the basolateral plasma membrane or to lysosomes, and localization to the trans-Golgi network (Mellman, 1996; Marks et al., 1997).

The neuron-specific alternatively spliced RSLE sequence in the $\mathrm{L} 1$ cytoplasmic domain is immediately preceded by a tyrosine residue. When the RSLE sequence is spliced in, the resulting YRSLE sequence conforms to the tyrosine-based sorting motif. In this paper, we demonstrate that the YRSLE sequence is critical for sorting L1 to the axonal growth cone, revealing a novel function of the RSLE exon in neurons.

\section{MATERIALS AND METHODS}

Generation of wild-type and mutant L1 expression vectors. The pBluescript II KS+, which contains a cDNA encoding the full-length human L1 $\left(\mathrm{L1}_{\mathrm{FL}}\right)$ in its EcoRI-HindIII site (Wong et al., 1995a), was mutagenized to create mutant L1 cDNAs. A cDNA encoding for either an RSLEminus form of L1 ( $\left.\mathrm{L1}_{\triangle \mathrm{RSLE}}\right)$ or mutant L1 with a Y1176A substitution $\left(\mathrm{L} 1_{\mathrm{Y} 1176 \mathrm{~A}}\right)$ was generated by oligonucleotide-directed mutagenesis according to the manufacturer's protocol (Clontech Laboratories, Palo Alto, CA). For both mutations, a selection primer (5'CTCCACCGCGGTGGATGCCGCTCTAGAAC-3') was used to mutate a unique NotI restriction site of pBluescript, which is located upstream from the L1 insert. A mutagenic primer (5'GACCTTCGGCGAGTACAGTGACAACGAGGAG-3' or 5' -GACCTTCGGCGAGGCCAGGTCCCTGGAGAG-3') was used for $\mathrm{L}_{\triangle \mathrm{RSLE}}$ or $\mathrm{L}_{\mathrm{Y} 1176 \mathrm{~A}}$, respectively. Both mutations were confirmed by dideoxy sequencing using Sequenase v2.0 (United States Biochemicals, Cleveland, $\mathrm{OH})$. A cDNA encoding for a truncation mutant of $\mathrm{L} 1\left(\mathrm{~L} 1_{\Delta \mathrm{C} 77}\right)$ that lacks the C-terminal 77 amino acids located immediately after the RSLE sequence was created by PCR. Primers used for the PCR amplification are as follows: a sense primer corresponding to nucleotides 2901-2918 of the L1 cDNA; an antisense primer (5'-CCAAGCTTACTTACCTACTCCAGGGACCTGTA-3') that contains a fragment corresponding to 3427-3441 ( $\left.\mathrm{Y}^{1176} \mathrm{RSLE}\right)$ followed immediately by a stop codon. The latter primer also has a HindIII restriction site added to its $5^{\prime}$-end. The PCR product was digested with BsiW I (located at 3015) and HindIII, and ligated into a BsiWI/HindIII-digested pBluescript containing the $\mathrm{L}_{\mathrm{FL}}$ cDNA. The entire PCR-amplified region was confirmed by sequencing.

Subsequently, the L1 cDNAs were excised from the pBluescript with $E c o$ RI and $X h o I$, and subcloned into the EcoRI/XhoI restriction site of pcDNA3 (Invitrogen, San Diego, CA). This placed the L1 cDNA under transcriptional control of a cytomegalo virus enhancer-promoter. The plasmid DNAs were purified using a Qiagen miniprep kit (Qiagen, Chatsworth, CA).

DNA transfection into NIH-3T3 cells and immunocytochemistry. NIH3T3 cells (American Type Culture Collection, Rockville, MD) were plated on a two-chamber plastic slide (Lab-Tek, Naperville, IL) coated with fibronectin $\left(5 \mu \mathrm{g} / \mathrm{cm}^{2}\right.$; Boehringer Mannheim, Indianapolis, IN) at a density of $\sim 0.5 \times 10^{5} \mathrm{cells} / \mathrm{cm}^{2}$ in minimum essential medium (MEM) (Life Technologies, Gaithersburg, MD) supplemented with $10 \%$ fetal bovine serum (FBS). After $16 \mathrm{hr}$, the cells were transfected with L1 expression plasmids by DOTAP liposomal transfection according to the manufacturer's protocol (Boehringer Mannheim). After an additional 24 hr incubation, the cells were processed for immunocytochemistry. For living cell staining, the cells were incubated with monoclonal anti-human L1 antibody (Wolff et al., 1988) for $1 \mathrm{hr}$ at $4^{\circ} \mathrm{C}$ followed by fixation with Bouin's fluid ( $75 \%$ saturated aqueous picric acid, $20 \%$ formalin, $5 \%$ glacial acetic acid) for $20 \mathrm{~min}$. For fixed cell staining, the cells were fixed with Bouin's fluid, washed with PBS, blocked with $20 \%$ horse serum in PBS (HS-PBS), and incubated with monoclonal anti-human L1 antibody for $16 \mathrm{hr}$ at $4^{\circ} \mathrm{C}$. In both staining procedures, the cells were then incubated with Texas Red-conjugated anti-mouse IgG (Molecular Probes, Eugene, OR) in HS-PBS (1:200) for $1 \mathrm{hr}$ at $20^{\circ} \mathrm{C}$, rinsed with PBS, mounted with SlowFade (Molecular Probes), and observed using a Zeiss LSM 410 confocal laser scan microscope (Carl Zeiss, Göttingen, Germany).

Primary cultures of DRG neurons and DNA transfection. DRGs were dissected from embryonic day 10 chicks and dissociated sequentially with $2.4 \mathrm{U} / \mathrm{ml}$ dispase II (Boehringer Mannheim) and $0.1 \mathrm{mg} / \mathrm{ml}$ DNase (Boehringer Mannheim) in $\mathrm{Ca}^{2+} / \mathrm{Mg}^{2+}$-free PBS. The dissociated cells were washed twice with MEM followed by incubation in MEM supplemented with $5 \mu \mathrm{g} / \mathrm{ml}$ DOTAP lipofection reagent for $10 \mathrm{~min}$. Subsequently, $2.5 \mu \mathrm{g} / \mathrm{ml}$ of plasmid DNA was added to the medium, and the cells were incubated for an additional $40 \mathrm{~min}$ on a culture dish. Then $10 \% \mathrm{FBS}$ and $20 \mathrm{ng} / \mathrm{ml}$ of nerve growth factor (NGF) were added, and the cells that were detached by shaking the dish were replated on a two-chamber plastic slide that was precoated sequentially with poly-Llysine and $10 \mu \mathrm{g} / \mathrm{ml}$ laminin (Life Technologies) at an initial density of $\sim 0.5 \times 10^{5} \mathrm{cells} / \mathrm{cm}^{2}$. The lipofection procedure described above is based on the improved method for DOTAP-mediated gene transfer into primary cultures of hippocampal neurons reported by Kaech et al. (1996).

For DRG neuronal culture without DNA transfection, the dissociated cells were resuspended in MEM supplemented with 10\% FBS and were preplated for $1 \mathrm{hr}$. Then $20 \mathrm{ng} / \mathrm{ml}$ of NGF was added to the medium, and the neuron-enriched culture was prepared by replating the detached cells on a poly-L-lysine and laminin-coated two-chamber slide at a density of $\sim 0.5 \times 10^{4}$ cells $/ \mathrm{cm}^{2}$.

The cultures were maintained in a humid atmosphere of $95 \%$ air, $5 \%$ $\mathrm{CO}_{2}$ at $37^{\circ} \mathrm{C}$.

Immunocytochemistry of DRG neurons. The DRG neurons were fixed with Bouin's fluid at 14 or $24 \mathrm{hr}$ after plating, washed with PBS, blocked with HS-PBS, and incubated with primary antibodies for $16 \mathrm{hr}$ at $4^{\circ} \mathrm{C}$. The primary antibodies used were monoclonal anti-human L1 (Wolff et al., 1988), polyclonal anti-chick NCAM (kind gift of Dr. Urs Rutishauser, Case Western Reserve University, Cleveland $\mathrm{OH})$, monoclonal antimicrotubule-associated protein-2 (MAP-2) $(5 \mu \mathrm{g} / \mathrm{ml}$; Boehringer Mannheim), and polyclonal anti-NgCAM antibodies (Lemmon and McLoon, 1986). After washes with PBS, the cells were incubated with Oregon Green-conjugated anti-rabbit IgG (Molecular Probes) and Texas Redconjugated anti-mouse IgG in HS-PBS $(1: 200)$ for $1 \mathrm{hr}$ at $20^{\circ} \mathrm{C}$, rinsed with PBS, and mounted with SlowFade.

In some experiments, cell-surface molecules were labeled by incubating living cells with monoclonal anti-human L1 and polyclonal anti-chick NCAM antibodies for $1 \mathrm{hr}$ at $37^{\circ} \mathrm{C}$. The cells were then fixed with $4 \%$ formaldehyde in PBS, followed by incubation with secondary antibodies.

Human L1-transfected neurons that were double-stained for chick NCAM and human L1 were observed using a Zeiss LSM 410 confocal laser scan microscope with an oil immersion $100 \times$ objective. The whole area of a Lab-Tek slide chamber was screened, and all the neurons expressing human L1 were included in this study. The cells were scanned, and fluorescence images were obtained in $0.5 \mu \mathrm{m}$ steps in the $z$-axis. A projected image was then generated from a series of sectional images that encompassed the entire cell (10-20 $\mu \mathrm{m}$ in the $z$-axis).

\section{RESULTS}

\section{Generation of L1 mutants and expression in NIH-3T3 cells}

The L1 cytoplasmic domain consists of 114 amino acids (11441257) (Hlavin and Lemmon, 1991), and a part of the cytoplasmic domain (1176-1185) is shown in the single-letter amino acid code (Fig. 1). In the wild-type full-length $\mathrm{L} 1\left(\mathrm{L1}_{\mathrm{FL}}\right)$, a tyrosine residue at position 1176 is adjacent to the RSLE sequence (shaded region), and the resulting sequence of YRSLE conforms to a tyrosine-based sorting motif, YxxL (underlined region). To characterize the structural significance of the YRSLE sequence for proper localization of L1 in neurons, we have generated one non-neuronal isoform and two mutant forms of L1. In the nonneuronal form of $\mathrm{L} 1$ lacking the RSLE sequence ( $\left.\mathrm{L} 1_{\triangle \mathrm{RSLE}}\right)$, a 

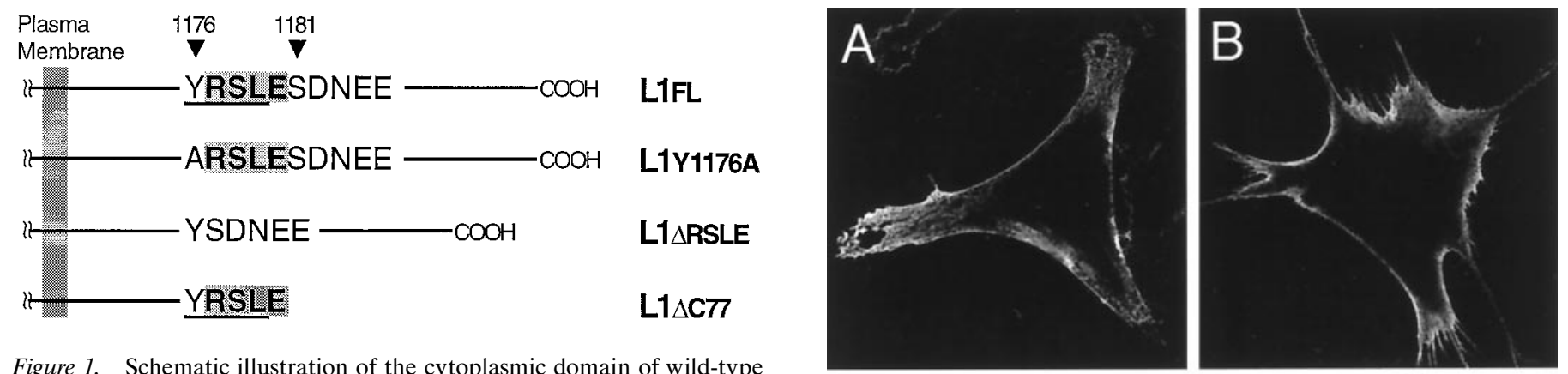

Figure 1. Schematic illustration of the cytoplasmic domain of wild-type and mutant forms of L1. A part of the L1 cytoplasmic domain is shown in the single-letter amino acid code. In the neuronal form of $\mathrm{L} 1\left(\mathrm{~L} 1_{\mathrm{FL}}\right)$, $\mathrm{Tyr}^{1176}$ is adjacent to the RSLE sequence (shaded region). The resulting sequence of YRSLE conforms to a tyrosine-based sorting motif, Yxx $\phi$ (underlined region), where $\mathrm{x}$ is any amino acid and $\phi$ is an amino acid with a bulky hydrophobic side chain. In the non-neuronal form of $\mathrm{L} 1$ ( $\left.\mathrm{L}_{\triangle \mathrm{RSLE}}\right)$ that lacks the RSLE sequence, a hydrophobic amino acid leucine at position $\mathrm{Y}+3$ is replaced by a polar amino acid, $\mathrm{Asn} . \mathrm{L}_{\mathrm{Y} 1176 \mathrm{~A}}$ has a single amino acid substitution (Y1176A) that mutates a critical tyrosine residue in the motif. $\mathrm{L} 1_{\Delta \mathrm{C} 77}$, which lacks the $\mathrm{C}$-terminal 77 amino acids located immediately after the RSLE exon, still carries the YRSLE sequence.

hydrophobic amino acid leucine at position $\mathrm{Y}+3$, which is a key residue in the motif, is replaced by a polar amino acid Asn. $\mathrm{L}_{\text {Y1176A }}$ has a single amino acid substitution (Y1176A) that mutates a critical tyrosine residue in the motif. $\mathrm{L}_{\Delta \mathrm{C} 77}$ is a truncation mutant that lacks the $\mathrm{C}$-terminal 77 amino acids located immediately after the RSLE sequence. Consequently, $\mathrm{L} 1_{\mathrm{FL}}$ and $\mathrm{L}_{\Delta \mathrm{C} 77}$ carry an amino acid sequence that conforms to the tyrosine-based sorting motif; however, this sequence is disrupted in $\mathrm{L}_{\triangle \mathrm{RSLE}}$ and $\mathrm{L}_{\mathrm{Y} 1176 \mathrm{~A}}$. We have generated pcDNA3-based expression plasmids containing human L1 cDNA that codes for $\mathrm{L}_{\mathrm{FL}}, \mathrm{L} 1_{\triangle \mathrm{RSLE}}, \mathrm{L} 1_{\mathrm{Y} 1176 \mathrm{~A}}$, or $\mathrm{L} 1_{\Delta \mathrm{C} 77}$. Both the extracellular and transmembrane domains are identical among all the forms of L1.

To show that the L1 constructs are processed correctly and that the gene products are integrated properly into the plasma membrane in nonpolarized cells, NIH-3T3 cells were transfected with the L1 expression plasmids. Both living cells and fixed cells were immunostained with monoclonal anti-human L1 antibody. Figure 2 shows single-section confocal images $(0.71-\mu \mathrm{m}$-thick) of the cells stained alive. $\mathrm{L}_{\mathrm{FL}}, \mathrm{L}_{\Delta \mathrm{RSLE}}, \mathrm{L}_{\mathrm{Y} 1176 \mathrm{~A}}$ and $\mathrm{L}_{\Delta \mathrm{C} 77}$ are expressed on the cell surface with a similar pattern in both living and fixed cells (data not shown), indicating that all the forms of L1 are integrated properly into the membrane in NIH-3T3 cells.

\section{The YRSLE sequence is required for sorting L1 to the axonal growth cone in DRG neurons}

To study axonal sorting of L1, we first characterized neurites from cultured DRG neurons (axons vs dendrites). Peripheral sensory neurons including DRG neurons are pseudounipolar in situ (Tandrup, 1995), and their somata lack dendrites (Pannese, 1981). An axon of DRG neurons bif urcates shortly after it emerges from the cell body: one branch extends peripherally, and the other branch extends centrally. Immunocytochemical studies showed that neurites from cultured DRG neurons express an axonal marker, L1, but not a dendritic marker, MAP-2 (Letourneau and Shattuck, 1989). Koninck et al. (1993) have shown that NGF induces sensory neurons from the nodose ganglia to extend dendrites if the neurons are cultured in the absence of satellite cells for a long term (1-3 weeks). To characterize neurites from DRG neurons under the culture conditions in the present study, the cells were double-labeled with polyclonal anti-NgCAM (a chick homolog of
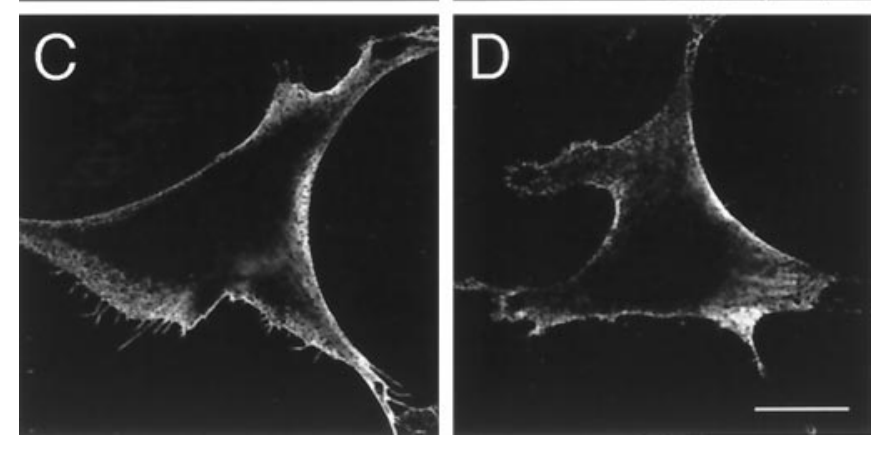

Figure 2. Cell surface expression of wild-type and mutant forms of L1 in NIH-3T3 cells. Immunocytochemical localization of $\mathrm{L} 1_{\mathrm{FL}}(A), \mathrm{L}_{\Delta \mathrm{RSLE}}$ $(B), \mathrm{L}_{\mathrm{Y} 1176 \mathrm{~A}}(C)$, and $\mathrm{L}_{\Delta \mathrm{C} 77}(D)$ in NIH-3T3 cells is shown. Live transfected cells were stained with anti-human L1 antibody, and singlesection confocal images $(0.71-\mu \mathrm{m}$-thick) were taken. All the forms of L1 are expressed on the cell surface with a similar pattern in both living and fixed cells (data not shown), indicating that they are correctly processed and integrated into the plasma membrane. Scale bar, $25 \mu \mathrm{m}$.
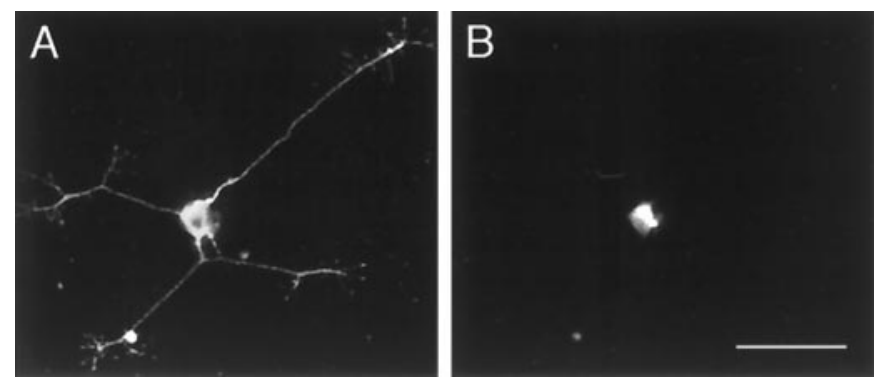

Figure 3. Immunocytochemical characterization of neurites from cultured DRG neurons. Immunofluorescence micrographs of a chick DRG neuron double-labeled with anti-NgCAM $(A)$ and anti-MAP-2 antibody $(B)$ are shown. All the neurites express an axonal marker, $\mathrm{NgCAM}$, but Scale bar, $50 \mu \mathrm{m}$.

L1) and monoclonal anti-MAP-2 antibodies (Fig. 3). All the neurites expressed NgCAM but not MAP-2 in 322 DRG neurons examined after $14 \mathrm{hr}$ in culture and in 346 neurons after $24 \mathrm{hr}$ in culture. Similar results have been reported by Honig and Kueter (1995) showing that all the growth cones of DRG explants expressed $\mathrm{NgCAM}$ after $1.5 \mathrm{~d}$ in culture. These findings indicate that DRG neurons used in the following experiments bear only axons and lack dendrites.

To study the role of the YRSLE sequence in the localization of L1 in neurons, primary cultures of chick DRG neurons were transfected with pcDNA3 containing human L1 cDNA that codes for $\mathrm{L}_{\mathrm{FL}}, \mathrm{L}_{\triangle \mathrm{RSLE}}, \mathrm{L}_{\mathrm{Y} 1176 \mathrm{~A}}$, or $\mathrm{L}_{\Delta \mathrm{C} 77}$. After 14 or $24 \mathrm{hr}$, expression of the transgene was visualized by immunocytochemistry using a monoclonal anti-human L1 antibody that does not the expression of a dendritic marker, MAP-2, is restricted to the cell body. 


\section{Chick NCAM}
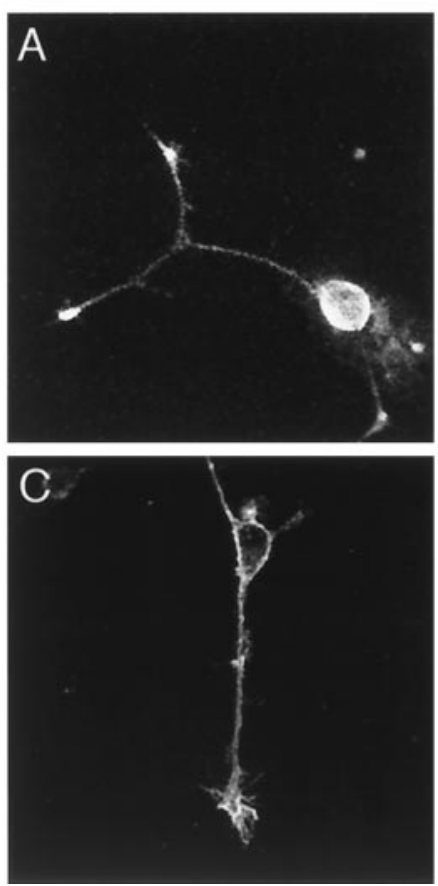

Human L1
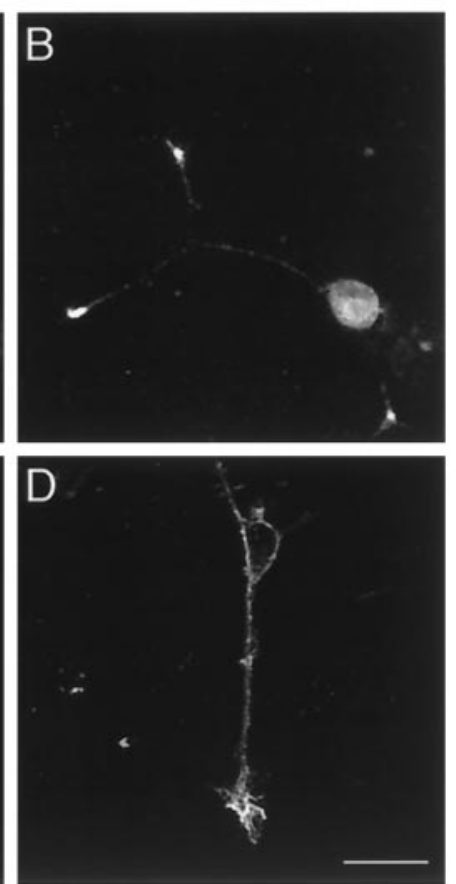

Figure 4. Subcellular localization of $\mathrm{L}_{\mathrm{FL}}(A, B)$ and $\mathrm{L}_{\Delta \mathrm{C} 77}(C, D)$ in DRG neurons. Projected confocal images of human L1-expressing DRG neurons at $14 \mathrm{hr}$ after transfection are shown. Expression of $\mathrm{L} 1_{\mathrm{FL}}$ or $\mathrm{L}_{\Delta \mathrm{C} 77}$ was visualized by monoclonal anti-human $\mathrm{L} 1$ antibody $(B, D)$. The cells were double-labeled with polyclonal anti-chick NCAM antibody to visualize the entire outline of neurons $(A, C)$. Both $\mathrm{L}_{\mathrm{FL}}$ and $\mathrm{L}_{\Delta \mathrm{C} 77}$ are highly expressed in the axonal growth cone and to a lesser degree in the cell body. Scale bar, $25 \mu \mathrm{m}$.

cross-react with NgCAM. The transfected cells were doublelabeled with polyclonal anti-chick NCAM antibody to visualize the entire outline of neurons. An $\mathrm{L1}_{\mathrm{FL}}$-expressing $\mathrm{DRG}$ neuron shown in Figure $4 A, B$ is representative of 11 cells from five independent experiments. $\mathrm{L} 1_{\mathrm{FL}}$ was highly expressed in the axonal growth cone and to a lesser degree in the cell body, consistent with the observation that L1 is preferentially transported to the axonal growth cone and inserted exclusively into the growth cone membrane in DRG neurons (Vogt et al., 1996). Similar results were obtained in all of the 11 cells, which expressed $\mathrm{L} 1_{\mathrm{FL}}$ (eight cells after $14 \mathrm{hr}$, three cells after $24 \mathrm{hr}$ ). These data also indicate that L1 can be synthesized from the transgene and transported to the growth cone within $14 \mathrm{hr}$ after transfection. $\mathrm{L}_{\triangle \mathrm{RSLE}}$-expressing DRG neurons shown in Figure 5 are representative of 23 cells from four independent experiments (13 cells after $14 \mathrm{hr}, 10$ cells after $24 \mathrm{hr}$ ). Expression of $\mathrm{L1}_{\triangle \mathrm{RSLE}}$ was restricted to the cell body, or in some neurons $\mathrm{L1}_{\Delta \mathrm{RSLE}}$ extended into the proximal axonal shaft. None of the 23 neurons expressed $\mathrm{L}_{\triangle \mathrm{RSLE}}$ either in the distal half of the axonal shaft or in the growth cone. The middle and bottom panels in Figure 5 show the most extreme examples of neurons grown for $14 \mathrm{hr}$ and $24 \mathrm{hr}$ after transfection, respectively, where $\mathrm{L}_{\triangle \mathrm{RSLE}}$ extended farthest into the axonal shaft. These data indicate that the RSLE sequence has to be spliced in for L1 to reach the growth cone in DRG neurons.

Because the RSLE sequence constitutes a tyrosine-based sorting motif in the L1 cytoplasmic domain, we then analyzed whether a mutation of the critical tyrosine residue in the motif influences the cellular localization of $\mathrm{L} 1 . \mathrm{L}_{\mathrm{Y} 1176 \mathrm{~A}}$-expressing DRG neurons shown in Figure 6 are representative of 23 cells

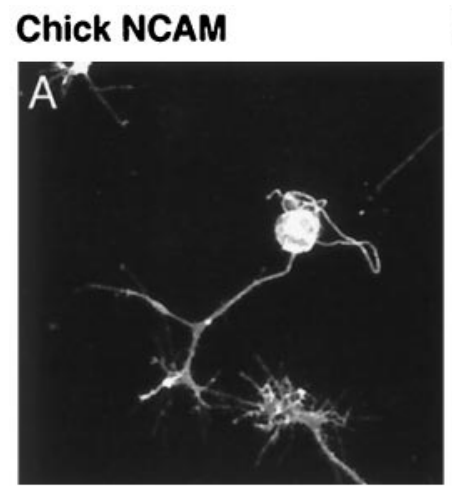

\section{Human L1}
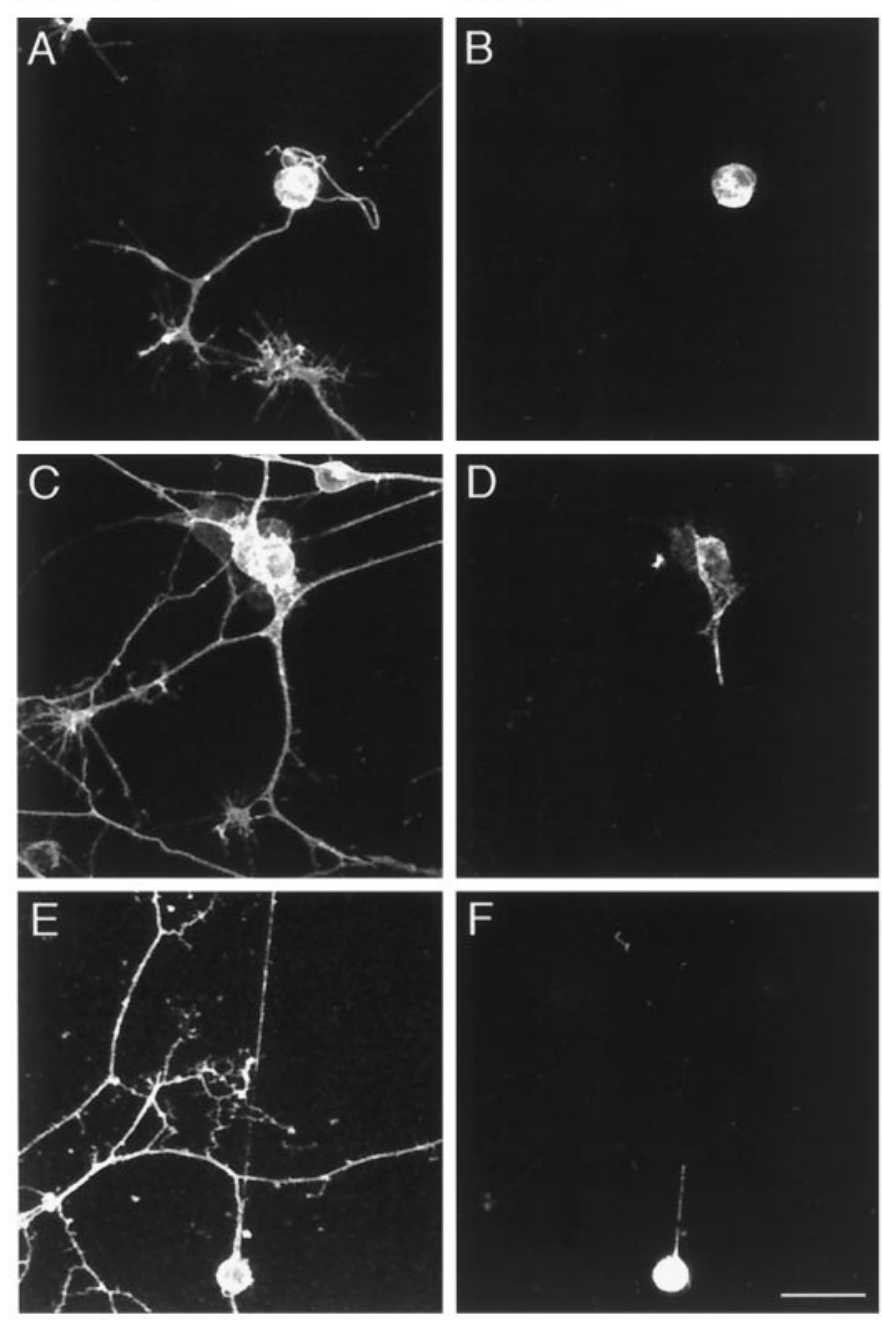

Figure 5. Subcellular localization of $\mathrm{L}_{\Delta \mathrm{RSLE}}$ in DRG neurons. Projected confocal images of $\mathrm{L}_{\triangle \mathrm{RSLE}}$-expressing DRG neurons at $14 \mathrm{hr}$ $(A-D)$ or $24 \mathrm{hr}(E, F)$ after transfection are shown. Expression of $\mathrm{L} 1_{\triangle \mathrm{RSLE}}$ was visualized by monoclonal anti-human $\mathrm{L} 1$ antibody $(B, D, F)$. The cells were double-labeled with polyclonal anti-chick NCAM antibody to visualize the entire outline of neurons $(A, C, E)$. Expression of $\mathrm{L}_{\triangle \mathrm{RSLE}}$ is restricted to the cell body $(B)$, or $\mathrm{L} 1_{\triangle \mathrm{RSLE}}$ extends into the proximal axonal shaft but does not reach the distal half of the axon and the growth cone $(D, F)$. Scale bar, $25 \mu \mathrm{m}$.

from four independent experiments ( 5 cells after $14 \mathrm{hr}$, 18 cells after $24 \mathrm{hr}$ ). Similar to the localization pattern of $\mathrm{L}_{\triangle \mathrm{RSLE}}$, expression of $\mathrm{L} 1_{\mathrm{Y} 1176 \mathrm{~A}}$ was restricted to the cell body and proximal axonal shaft, and never extended into the distal axonal shaft or growth cone. This observation indicates that $\mathrm{Tyr}^{1176}$ as well as the RSLE sequence is critical for targeting L1 to the axonal growth cone. $\mathrm{L} 1_{\Delta \mathrm{C} 77}$, which carries the YRSLE sequence, consistently reached the axonal growth cone in 19 of 20 DRG neurons from three independent experiments (9 cells after $14 \mathrm{hr}$, 11 cells after $24 \mathrm{hr}$ ). A representative $\mathrm{L}_{\Delta \mathrm{C} 77^{-}}$-expressing cell is shown in Figure $4 C, D$. The localization pattern of $\mathrm{L} 1_{\Delta C 77}$ was similar to that of $\mathrm{L} 1_{\mathrm{FL}}$, with one exception in which $\mathrm{L} 1_{\Delta \mathrm{C} 77}$ stayed in the cell body and proximal axonal shaft.

These observations are summarized in Table 1, where the subcellular localization of transfected L1 in DRG neurons was categorized into four groups on the basis of the extent of L1 


\section{Chick NCAM}

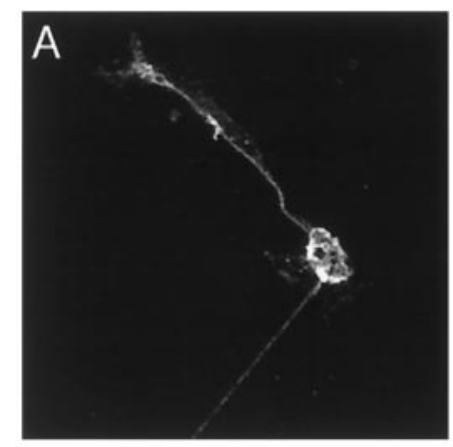

\section{Human L1}

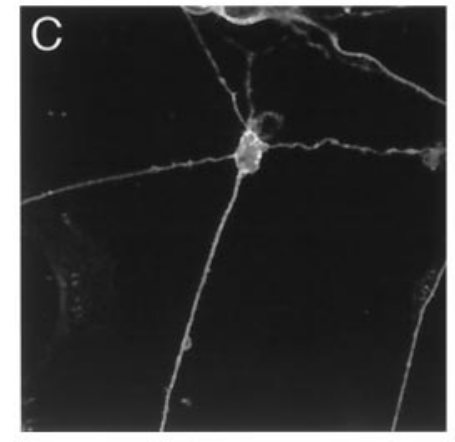

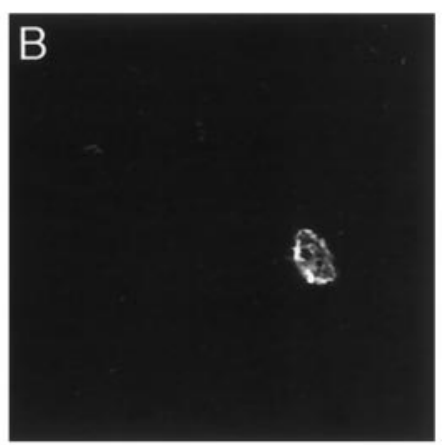

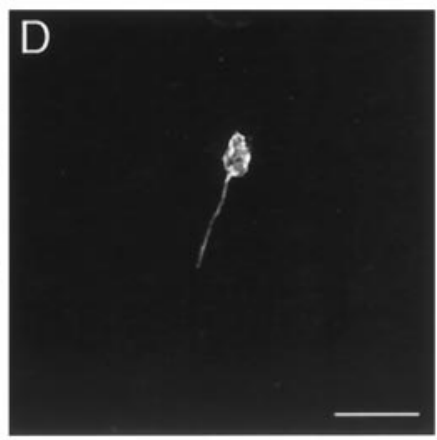

Figure 6. Subcellular localization of $\mathrm{L}_{\mathrm{Y} 1176 \mathrm{~A}}$ in $\mathrm{DRG}$ neurons. Projected confocal images of $\mathrm{L}_{\mathrm{Y} 1176 \mathrm{~A}}$-expressing $\mathrm{DRG}$ neurons at $14 \mathrm{hr}(A$, $B)$ or $24 \mathrm{hr}(C, D)$ after transfection are shown. Expression of $\mathrm{L}_{\mathrm{Y} 1176 \mathrm{~A}}$ was visualized by monoclonal anti-human L1 antibody $(B, D)$. The cells were double-labeled with polyclonal anti-chick NCAM antibody to visualize the entire outline of neurons $(A, C)$. Expression of $\mathrm{L1}_{\mathrm{Y} 1176 \mathrm{~A}}$ is restricted to the cell body $(B)$, or $\mathrm{Ll}_{\mathrm{Y} 1176 \mathrm{~A}}$ extends into the proximal axonal shaft but does not reach the distal half of the axon and the growth cone $(D)$. Scale bar, $25 \mu \mathrm{m}$.

expression along the axonal shaft. These results demonstrate that the YRSLE sequence is required for targeting L1 to the axonal growth cone, and that the tyrosine residue is critical for the function of this signal.

The failure of $\mathrm{L} 1_{\triangle \mathrm{RSLE}}$ and $\mathrm{L} 1_{\mathrm{Y} 1176 \mathrm{~A}}$ to follow the proper transport pathway raises a question as to whether these forms of L1 are on the cell surface or trapped within intracellular vesicles. Living DRG neurons that express either $\mathrm{L} 1_{\triangle \mathrm{RSLE}}$ or $\mathrm{L} 1_{\mathrm{Y} 1176 \mathrm{~A}}$ were incubated with the anti-human L1 antibody before fixation, and confocal sections $(0.83-\mu \mathrm{m}$-thick) through the middle of the cell body were obtained (Fig. 7). Both forms of L1 mostly overlapped with chick NCAM on the cell surface, as evidenced by a yellow color in the superimposed images where chick NCAM is colored green and transfected L1 is red. These observations indicate that these forms of L1 are integrated into the plasma membrane in the somata after missorting.

\section{DISCUSSION}

The interaction between cytoplasmic coat proteins and specific signals in the cytoplasmic domains of integral membrane proteins is a general mechanism controlling protein sorting. The bestcharacterized sorting signal is the tyrosine-based sorting motif that is involved in various sorting events by interaction with adaptor proteins (Trowbridge et al., 1993; Mellman, 1996; Marks et al., 1997). The YRSLE sequence present in the cytoplasmic domain of the neuronal form of L1 conforms to the tyrosinebased sorting motif. We have found that the AP-2 adaptor specifically recognizes and interacts with the YRSLE sequence, resulting in clathrin-mediated endocytosis of L1 (H. Kamiguchi, K. E. Long, M. Pendergast, A. W. Schaefer, I. Rapoport, T. Kirchhausen, and V. Lemmon, unpublished observations). These observations indicate that the YRSLE sequence of L1 actually functions as a tyrosine-based sorting signal. The L1 cytoplasmic domain contains three other tyrosine residues (Hlavin and Lemmon, 1991), although none is situated three amino acids $\mathrm{N}$-terminal to a hydrophobic residue and therefore do not constitute a recognized sorting sequence. Homologs of mammalian L1 in chick (NgCAM/8D9/G4) and zebrafish (L1.1 and L1.2) contain the YRSLE sequence, but it is absent in Drosophila (neuroglian) (Tongiorgi et al., 1995; Hortsch, 1996). In addition, it is conserved in two other members of the L1 subfamily, neurofascin and NrCAM (Kayyem et al., 1992; Volkmer et al., 1992), implying an important function for this sequence.

The tyrosine-based sorting motif in the L1 cytoplasmic domain is immediately followed by a cluster of acidic amino acids containing Ser ${ }^{1181}$ that can be phosphorylated by casein kinase II (CKII) in vivo and in vitro (Fig. 1) (Wong et al., 1996). Interestingly, an acidic stretch with CKII phosphorylation sites is also located C-terminal to a tyrosine-based signal in several proteins that are targeted to post-Golgi compartments, such as furin, mannose 6-phosphate receptors, and varicella-zoster virus glycoprotein I. Intracellular trafficking of these proteins is regulated by the CKII phosphorylation sites as well as by the tyrosine-based sorting signal (Trowbridge et al., 1993; Jones et al., 1995; Takahashi et al., 1995; Alconada et al., 1996; Breuer et al., 1997), implying that the phosphorylation of L1 by CKII might play a role in L1 trafficking.

Maintenance of spatial distribution of integral membrane proteins is an essential function of polarized cells. This is evident in developing neurons in which the production of specific cellsurface domains is necessary to explore guidance cues and coordinate axonal growth, to establish appropriate connections with their targets, and to transmit or receive both chemical and electrical information. Because L1 expressed in the growth cone plays a crucial role in regulating axonal growth, it is important for developing neurons to maintain the polarized expression of L1 by preferentially targeting both newly synthesized and recycled L1 molecules to the axonal growth cone. The present study demonstrates that the YRSLE sequence of the L1 cytoplasmic domain functions as a tyrosine-based sorting signal that is required for sorting L1 to the axonal growth cone. This result strongly suggests that neurons express an intracellular adaptor-like molecule that specifically recognizes and interacts with the YRSLE sequence, resulting in sorting L1 into a specific population of vesicles destined for the axonal growth cone. Functional interactions between tyrosine-based sorting signals and adaptor proteins depend on multiple factors, such as the exact position of the signal in the cytoplasmic tail (Rohrer et al., 1996), amino acids surrounding the critical tyrosine (Ohno et al., 1996), and possible secondary signals that operate in concert (Rohrer et al., 1995; Schweizer et al., 1996). Therefore, although the YRSLE sequence is essential for sorting to axons, it is likely that additional features of the L1 cytoplasmic domain N-terminal to this sequence are also important for targeting to the axon.

The mechanism of protein sorting is well characterized in polarized epithelial cells (Matter and Mellman, 1994; Mellman, 1996). The cytoplasmic domain of some integral membrane proteins contains tyrosine-based sorting signals that mediate sorting to the basolateral plasma membrane. The AP-1 adaptor specifically localizes to coated buds and vesicles of the trans-Golgi 


\begin{tabular}{lcccc}
\hline Table 1. DRG neurons expressing transfected L1 in specific cell locations & \\
Transfected L1 & $\mathrm{L}_{\mathrm{FL}}$ & $\mathrm{L1}_{\Delta \mathrm{RSLE}^{*}}$ & $\mathrm{~L}_{\mathrm{Y}_{1176 \mathrm{~A}^{*}}}$ & $\mathrm{~L}_{\Delta \mathrm{C} 77}$ \\
\hline Restricted to the cell body & 0 & 11 & 11 & 0 \\
In the cell body and proximal axonal shaft & & & & \\
$\quad$ Within a diameter of the cell body & 0 & 8 & 6 & 0 \\
$\quad$ Within a proximal half of the axonal shaft & 0 & 4 & 6 & 1 \\
Reaches the growth cone & 11 & 0 & 0 & 19 \\
Total & 11 & 23 & 23 & 20
\end{tabular}

$\overline{\text { Subcellular localization of transfected L1 in dorsal root ganglion (DRG) neurons was categorized into four groups on the }}$ basis of the extent of L1 expression along the axonal shaft. Results are expressed as the numbers of DRG neurons expressing each form of L1. A Kruskal-Wallis test showed that there is a significant difference in L1 localization, depending on the form of transfected L1 $(p<0.0001)$.

${ }^{*} p<0.0001$; Mann-Whitney $U$ test compared with both $\mathrm{L}_{\mathrm{FL}}$ and $\mathrm{L} 1_{\Delta \mathrm{C} 77}$.

Figure 7. Cell surface localization of $\mathrm{L}_{\triangle \mathrm{RSLE}}$ and $\mathrm{L}_{\mathrm{Y} 1176 \mathrm{~A}}$ in the DRG somata. Confocal sections $(0.83-\mu \mathrm{m}$-thick) through the middle of the cell body of DRG neurons that express $\mathrm{L} 1_{\triangle \mathrm{RSLE}}$ $(A-C)$ or $\mathrm{L}_{\mathrm{Y} 1176 \mathrm{~A}}(D-F)$ are shown. The living cells were double-labeled with polyclonal antichick NCAM $(A, D)$ and monoclonal anti-human L1 antibody $(B, E)$. Superimposition of the images with chick NCAM colored in green and transfected $\mathrm{L} 1$ in red $(C, F)$ exhibits clear overlap (yellow) on the cell surface. Scale bar, $5 \mu \mathrm{m}$.

\section{Chick NCAM}
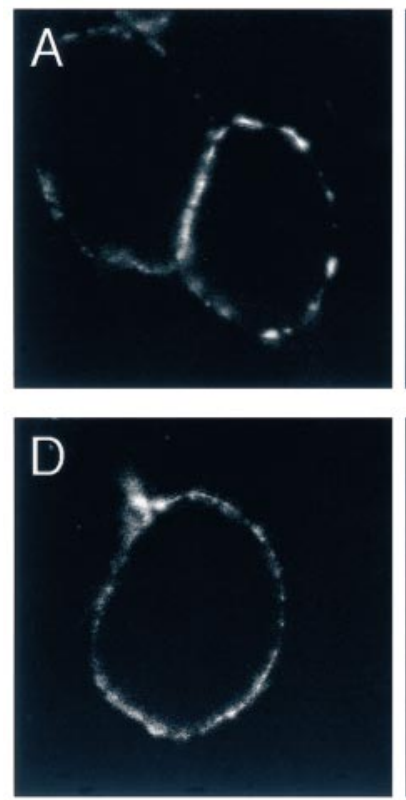

\section{Human L1}
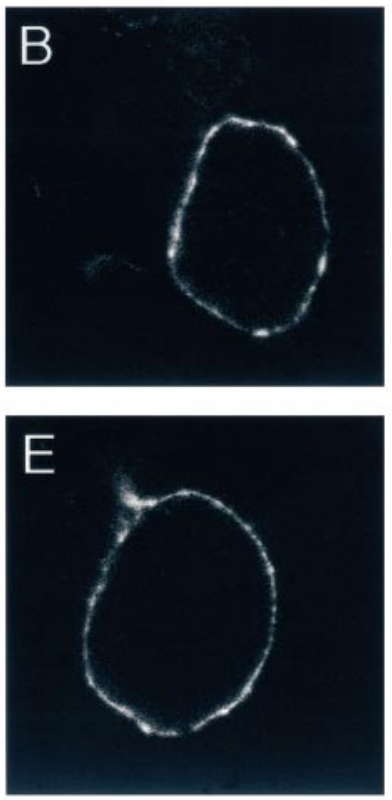

Chick NCAM (green) Human L1 (red)
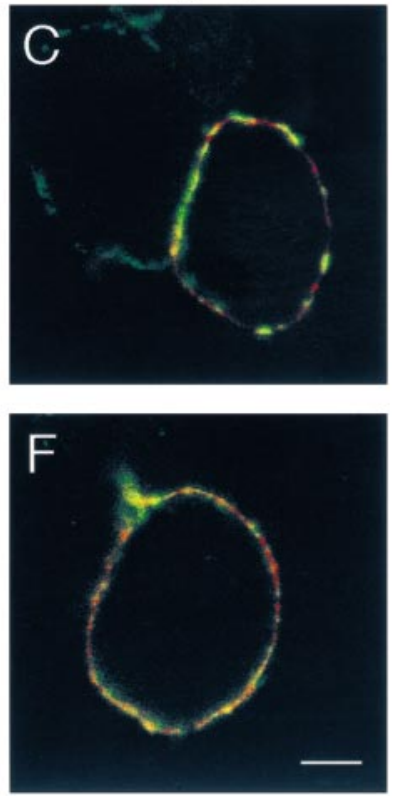

network, the primary sorting site of newly synthesized proteins, and mediates vesicular transport to the basolateral plasma membrane. Accumulating evidence has suggested that epithelial apical and neuronal axonal membranes, as well as epithelial basolateral and neuronal somatodendritic membranes, may be equivalent domains in terms of polarized protein localization (Craig and Banker, 1994; Scannevin et al., 1996). This has led to the proposal that epithelial cells and neurons may share common molecular mechanisms for protein sorting. However, several membrane proteins that contradict this hypothesis have also been reported (Craig and Banker, 1994; Higgins et al., 1997). Given the existence of nervous tissue-specific isoforms of adaptor complex subunits (Pevsner et al., 1994; Ball et al., 1995), it is most likely that neurons and epithelial cells use similar but distinct molecules to govern protein sorting. To further clarify the mechanism of protein sorting in neurons, it is essential to identify molecules that interact with tyrosine-based sorting signals and mediate axonal sorting.

Interestingly, expression of the YRSLE sequence depends on the neuron-specific alternatively spliced exon 27 that codes for RSLE. In the RSLE-minus form of L1 that is expressed exclusively in non-neuronal cells, the critical leucine residue at position
$\mathrm{Y}+3$ is replaced by a polar amino acid, Asn, resulting in disruption of the sorting signal. Functional differences between the RSLE-positive and RSLE-negative forms of L1 have been studied using L1-transfected L cells (Takeda et al., 1996). The cells expressing either form of L1 showed homophilic adhesivity and promoted neurite growth and neuronal migration to a similar extent, but the RSLE-positive L1-expressing cells migrated faster than the other cell line on an L1 substrate. However, the question regarding the function of the RSLE exon in neurons remained unanswered. Our findings showed that the RSLE exon regulates sorting into the axon. Non-neuronal cells that express the RSLEminus form of L1, such as Schwann cells, melanocytes, and lymphocytes, do not require the YRSLE sequence as a sorting signal, probably because these cells are not highly polarized.

Another possible function of the YRSLE sequence in neurons is that it may interact with Src homology 2 (SH2)-containing signaling proteins (Songyang and Cantley, 1995). Indeed, it has been demonstrated that the cytoplasmic domain of L1 is phosphorylated on tyrosine, possibly on Try ${ }^{1176}$ (Heiland et al., 1996). Because the tyrosine in the sorting motif has to be in a nonphosphorylated state for the signal to be active (Boll et al., 1996; Ohno et al., 1996), the YRSLE sequence might have dual roles (sorting 
signal or SH2 binding) depending on the phosphorylation state of the tyrosine.

In humans, mutations of the L1 gene cause hydrocephalus as well as disruptions of the formation of major axonal tracts such as the corticospinal tract and corpus callosum. Patients with L1 mutations almost always have spastic paraparesis and adducted thumbs, which are caused by impaired formation of the corticospinal tract and loss of innervation to the extensor pollicis muscle, respectively (Wong et al., 1995b; Kamiguchi et al., 1998). Interestingly, mutations that affect only the L1 cytoplasmic domain are much less likely to cause severe hydrocephalus than mutations affecting the extracellular domain (Yamasaki et al., 1997). However, mutations of the cytoplasmic domain are just as likely to produce abnormal development of axonal pathways as mutations of the extracellular domain. Because deletion of the cytoplasmic domain from L1 does not alter its homophilic adhesive property (Wong et al., 1995a), the cytoplasmic domain must serve other important roles that are critical in axonal tract development. This is likely to include activation of second messenger systems and interactions with the cytoskeleton (Kamiguchi and Lemmon, 1997). Mutations of the cytoplasmic domain must impair one or more of these L1 functions, resulting in abnormal development of major axon tracts. However, it is possible that mutations affecting the YRSLE sorting signal may also prevent L1 from being expressed in axons. So far, two different mutations that disrupt the YRSLE sequence in human L1 have been published: a frameshift mutation in exon 26 (Jouet et al., 1994) and a point mutation in the acceptor site in intron 26 that would truncate the protein immediately before the RSLE sequence (Jouet et al., 1995). Both mutations cause spastic paraparesis and adducted thumbs, but neither causes progressive hydrocephalus or death at an early age. In the affected individuals, loss of L1 expression in axons probably accounts for the malformation of axonal tracts.

\section{REFERENCES}

Alconada A, Bauer U, Hoflack B (1996) A tyrosine-based motif and a casein kinase II phosphorylation site regulate the intracellular trafficking of the varicella-zoster virus glycoprotein I, a protein localized in the trans-Golgi network. EMBO J 15:6096-6110.

Ball CL, Hunt SP, Robinson MS (1995) Expression and localization of $\alpha$-adaptin isoforms. J Cell Sci 108:2865-2875.

Barami K, Kirschenbaum B, Lemmon V, Goldman SA (1994) $\mathrm{N}$-cadherin and $\mathrm{Ng}$-CAM/8D9 are involved serially in the migration of newly generated neurons into the adult songbird brain. Neuron 13:567-582.

Boll W, Ohno H, Songyang Z, Rapoport I, Cantley LC, Bonifacino JS, Kirchhausen $T$ (1996) Sequence requirements for the recognition of tyrosine-based endocytic signals by clathrin AP-2 complexes. EMBO J 15:5789-5795.

Breuer P, Körner C, Böker C, Herzog A, Pohlmann R, Braulke T (1997) Serine phosphorylation site of the $46 \mathrm{kDa}$ mannose 6-phosphate receptor is required for transport to the plasma membrane in Madin-Darby canine kidney and mouse fibroblast cells. Mol Biol Cell 8:567-576.

Burden-Gulley SM, Lemmon V (1996) L1/8D9, N-cadherin and laminin induce distinct distribution patterns of cytoskeletal elements in growth cones. Cell Motil Cytoskel 35:1-23.

Burden-Gulley SM, Payne HR, Lemmon V (1995) Growth cones are actively influenced by substrate-bound adhesion molecules. J Neurosci 15:4370-4381.

Cohen NR, Taylor JSH, Scott LB, Guillery RW, Soriano P, Furley AJW (1997) Errors in corticospinal axon guidance in mice lacking the neural cell adhesion molecule L1. Curr Biol 8:26-33.

Craig AM, Banker G (1994) Neuronal polarity. Annu Rev Neurosci 17:267-310.

Craig AM, Wyborski RJ, Banker G (1995) Preferential addition of newly synthesized membrane protein at axonal growth cones. Nature 375:592-594.

Dahme M, Bartsch U, Martini R, Anliker B, Schachner M, Mantei N
(1997) Disruption of the mouse L1 gene leads to malformations of the nervous system. Nat Genet 17:346-349.

Grumet M, Edelman GM (1988) Neuron-glia cell adhesion molecule interacts with neurons and astroglia via different binding mechanisms. J Cell Biol 106:487-503.

Heiland PC, Hertlein B, Traub O, Griffith LS, Schmitz B (1996) The neural adhesion molecule L1 is phosphorylated on tyrosine and serine residues. NeuroReport 7:2675-2678.

Higgins D, Burack M, Lein P, Banker G (1997) Mechanisms of neuronal polarity. Curr Opin Neurobiol 7:599-604.

Hlavin ML, Lemmon V (1991) Molecular structure and functional testing of human L1CAM: an interspecies comparison. Genomics 11:416-423.

Honig MG, Kueter J (1995) The expression of cell adhesion molecules on the growth cones of chick cutaneous and muscle sensory neurons. Dev Biol 167:563-583.

Hortsch M (1996) The L1 family of neural cell adhesion molecules: old proteins performing new tricks. Neuron 17:587-593.

Jones BG, Thomas L, Molloy SS, Thulin CD, Fry MD, Walsh KA, Thomas G (1995) Intracellular trafficking of furin is modulated by the phosphorylation state of a casein kinase II site in its cytoplasmic tail. EMBO J 14:5869-5883.

Jouet M, Rosenthal A, Armstrong G, MacFarlane J, Stevenson R, Paterson J, Metzenberg A, Ionasescu V, Temple K, Kenwrick S (1994) X-linked spastic paraplegia (SPG1), MASA syndrome and X-linked hydrocephalus result from mutations in the L1 gene. Nat Genet 7:402-407.

Jouet M, Moncla A, Paterson J, Mckeown C, Fryer A, Carpenter N, Holmberg E, Wadelius C, Kenwrick S (1995) New domains of neural cell-adhesion molecule L1 implicated in X-linked hydrocephalus and MASA syndrome. Am J Hum Genet 56:1304-1314.

Kaech S, Kim JB, Cariola M, Ralston E (1996) Improved lipid-mediated gene transfer into primary cultures of hippocampal neurons. Mol Brain Res 35:344-348.

Kamiguchi H, Lemmon V (1997) Neural cell adhesion molecule L1: signaling pathways and growth cone motility. J Neurosci Res 49:1-8.

Kamiguchi H, Hlavin ML, Yamasaki M, Lemmon V (1998) Adhesion molecules and inherited diseases of the human nervous system. Annu Rev Neurosci 21:97-125.

Kayyem JF, Roman JM, de la Rosa EJ, Schwarz U, Dreyer WJ (1992) Bravo/Nr-CAM is closely related to the cell adhesion molecules L1 and $\mathrm{Ng}-\mathrm{CAM}$ and has a similar heterodimer structure. J Cell Biol 118:1259-1270

Koninck PD, Carbonetto S, Cooper E (1993) NGF induces neonatal rat sensory neurons to extend dendrites in culture after removal of satellite cells. J Neurosci 13:577-585.

Lagenaur C, Lemmon V (1987) An L1-like molecule, the 8D9 antigen, is a potent substrate for neurite extension. Proc Natl Acad Sci USA 84:7753-7757.

Lemmon V, McLoon S (1986) The appearance of an L1-like molecule in the chick primary visual pathway. J Neurosci 6:2987-2994.

Lemmon V, Farr K, Lagenaur C (1989) L1-mediated axon outgrowth occurs via a homophilic binding mechanism. Neuron 2:1597-1603.

Letourneau PC, Shattuck TA (1989) Distribution and possible interactions of actin-associated proteins and adhesion molecules of nerve growth cones. Development 105:505-519.

Lindner J, Rathjen FG, Schachner M (1983) L1 mono- and polyclonal antibodies modify cell migration in early postnatal mouse cerebellum. Nature 305:427-430.

Marks MS, Ohno H, Kirchhausen T, Bonifacino JS (1997) Protein sorting by tyrosine-based signals: adapting to the Ys and wherefores. Trends Cell Biol 7:124-128.

Matter K, Mellman I (1994) Mechanisms of cell polarity: sorting and transport in epithelial cells. Curr Opin Cell Biol 6:545-554.

Mellman I (1996) Endocytosis and molecular sorting. Annu Rev Cell Dev Biol 12:575-625.

Miura M, Kobayashi M, Asou H, Uyemura K (1991) Molecular cloning of cDNA encoding the rat neural cell adhesion molecule L1-two L1 isoforms in the cytoplasmic region are produced by differential splicing. FEBS Lett 289:91-95.

Moos M, Tacke R, Scherer H, Teplow D, Fruh K, Schachner M (1988) Neural adhesion molecule L1 as a member of the immunoglobulin superfamily with binding domains similar to fibronectin. Nature 334:701-703.

Ohno H, Fournier MC, Poy G, Bonifacino JS (1996) Structural determi- 
nants of interaction of tyrosine-based sorting signals with the adaptor medium chains. J Biol Chem 271:29009-29015.

Pannese E (1981) The satellite cells of the sensory ganglion. Adv Anat Embryol Cell Biol 65:1-111.

Persohn E, Schachner M (1990) Immunohistological localization of the neural adhesion molecules L1 and N-CAM in the developing hippocampus of the mouse. J Neurocytol 19:807-819.

Pevsner J, Volknandt W, Wong BR, Scheller RH (1994) Two rat homologs of clathrin-associated adaptor proteins. Gene 146:279-283.

Reid RA, Hemperly JJ (1992) Variants of human L1 cell adhesion molecule arise through alternate splicing of RNA. J Mol Neurosci 3:127-135.

Rohrer J, Schweizer A, Johnson KF, Kornfeld S (1995) A determinant in the cytoplasmic tail of the cation-dependent mannose 6-phosphate receptor prevents trafficking to lysosomes. J Cell Biol 130:1297-1306.

Rohrer J, Schweizer A, Russell D, Kornfeld S (1996) The targeting of Lamp1 to lysosomes is dependent on the spacing of its cytoplasmic tail tyrosine sorting motif relative to the membrane. J Cell Biol 132:565-576.

Rothman JE, Wieland FT (1996) Protein sorting by transport vesicles. Science 272:227-234.

Scannevin RH, Murakoshi H, Rhodes KJ, Trimmer JS (1996) Identification of a cytoplasmic domain important in the polarized expression and clustering of the $\mathrm{Kv} 2.1 \mathrm{~K}^{+}$channel. J Cell Biol 135:1619-1632.

Schweizer A, Kornfeld S, Rohrer J (1996) Cysteine ${ }^{34}$ of the cytoplasmic tail of the cation-dependent mannose 6-phosphate receptor is reversibly palmitoylated and required for normal trafficking and lysosomal enzyme sorting. J Cell Biol 132:577-584.

Songyang Z, Cantley LC (1995) Recognition and specificity in protein tyrosine kinase-mediated signaling. Trends Biol Sci 20:470-475.

Stallcup WB, Beasley L (1985) Involvement of the nerve growth factor-inducible large external glycoprotein (NILE) in neurite fasciculation in primary cultures of rat brain. Proc Natl Acad Sci USA 82:1276-1280.

Takahashi S, Nakagawa T, Bonno T, Watanabe T, Murakami K, Nakayama K (1995) Localization of furin to the trans-Golgi network and recycling from the cell surface involves Ser and Tyr residues within the cytoplasmic domain. J Biol Chem 270:28397-28401.
Takeda Y, Asou H, Murakami Y, Miura M, Kobayashi M, Uyemura K (1996) A nonneuronal isoform of cell adhesion molecule L1: tissuespecific expression and functional analysis. J Neurochem 66:2338-2349.

Tandrup T (1995) Are the neurons in the dorsal root ganglion pseudounipolar? A comparison of the number of neurons and number of myelinated and unmyelinated fibres in the dorsal root. J Comp Neurol 357:341-347.

Tongiorgi E, Bernhardt RR, Schachner M (1995) Zebrafish neurons express two L1-related molecules during early axonogenesis. J Neurosci Res 42:547-561.

Trowbridge IS, Collawn JF, Hopkins CR (1993) Signal-dependent membrane protein trafficking in the endocytic pathway. Annu Rev Cell Biol 9:129-161.

Vogt L, Giger RJ, Ziegler U, Kunz B, Buchstaller A, Hermens WTJMC, Kaplitt MG, Rosenfeld MR, Plaff DW, Verhaagen J, Sonderegger P (1996) Continuous renewal of the axonal pathway sensor apparatus by insertion of new sensor molecules into the growth cone membrane. Curr Biol 6:1153-1158.

Volkmer H, Hassel B, Wolff JM, Frank R, Rathjen FG (1992) Structure of the axonal surface recognition molecule neurofascin and its relationship to a neural subgroup of the immunoglobulin superfamily. J Cell Biol 118:149-161.

Wolff JM, Frank R, Mujoo K, Spiro RC, Reisfeld RA, Rathjen FG (1988) A human brain glycoprotein related to the mouse cell adhesion molecule L1. J Biol Chem 263:11943-11947.

Wong EV, Cheng G, Payne HR, Lemmon V (1995a) The cytoplasmic domain of the cell adhesion molecule L1 is not required for homophilic adhesion. Neurosci Lett 200:155-158.

Wong EV, Kenwrick S, Willems P, Lemmon V (1995b) Mutations in the cell adhesion molecule L1 cause mental retardation. Trends Neurosci $18: 168-172$

Wong EV, Schaefer AW, Landreth G, Lemmon V (1996) Casein kinase II phosphorylates the neural cell adhesion molecule L1. J Neurochem 66:779-786.

Yamasaki M, Thompson P, Lemmon V (1997) CRASH syndrome: mutations in L1CAM correlate with severity of the disease. Neuropediatrics 28:175-178. 